\title{
Forming Anti-Racist and Counter-Hegemonic Spaces
}

\author{
SHAWHIN ROUDBARI \\ University of Colorado Boulder
}

\section{ANA COLÓN QUIÑONES}

University of Colorado Boulder

Racism persists in the work we do as architects, architecture students, and architectural educators. In this paper, we combine sociological theories of colorblind racism and white hegemony with an analysis of architectural design processes. We draw from writings, poetry, imagery, and renderings as media that aid in making architecture's racial discrimination visible. We propose ways of thinking about colorblind racism in design that we hope will aid design practitioners, students, and teachers in countering hegemonic racist ideologies that are present in our work. We consider ways that in our practices and our teaching, we conceptualize space as colorblind, we render those spaces as white, hegemonic, and normative, and we disengage when those spaces sustain racism. We argue that our failure to see the racialization of the spaces we imagine is an expression of colorblind racism.

\section{INTRODUCTION}

"Well, plans and sections as drawings are inherently racist." The idea, perhaps more radical sounding than actually provocative, was shared by a participant in our workshop on racism and design at the Association of Collegiate Schools of Architecture (ACSA) fall 2019 conference. The phrase sounded more contentious than the reaction it provoked because most folks in the room seemed to understand the premise of the comment. If debated, we imagine differences of opinion would emerge. Most in the room appeared to recognize that rational, measured forms of recording, communicating, and delineating space were among the many tools that enabled and were enabled by colonialism. In the US, modern racism joined the history of colonial violence since the slave revolts and subsequent racial formations in the US. The rational regulation and segregation of spaces and the bodies that occupy them implicate plans and sections in our racist history. This was the understanding that was presumed evoked by the participant in our workshop.

The reaction--or lack thereof--to their statement reminds us of the distinction between racist actions that are obvious enough to denounce and those racist actions that are hidden in ways that we are blind to. This distinction between forms of racism underscores how racist ideologies are hegemonic and how they show up in architecture. Racist ideologies serve those in power and are perpetuated through people's thoughts and actions. At the workshop, we were reminded

\author{
ANN MARIE DANG \\ University of Colorado Boulder
}

that in architecture, the hegemony of racist ideologies is present even in our drawing conventions. (That this is obvious to a few and hard to grasp for most speaks to the power of hegemonic ideologies.)

In this paper, as in our conference session, we hope to make visible the hegemonic ways that racism persists in the work we do as architects, architecture students, and architectural educators. We combine sociological theories of colorblind racism and white hegemony with an analysis of architectural design processes. We draw from writings, poetry, imagery, and renderings as media that aid in making architecture's racial discrimination visible. We propose ways of thinking about colorblind racism in space that we hope will aid design practitioners, students, and teachers in countering hegemonic racist ideologies that are present in our work. To achieve this, our paper is structured as a series of vignettes that express the range of ways racism is perpetuated and inflicted through architecture.

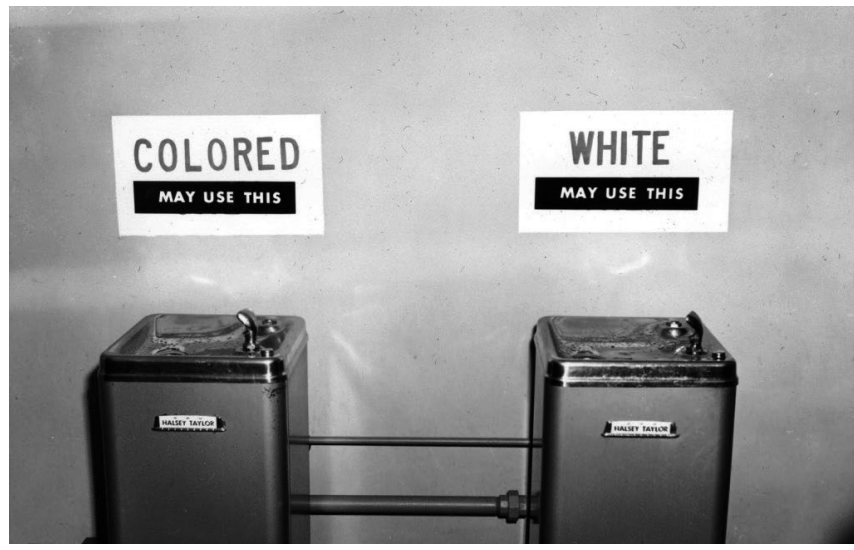

Figure 1. Segregation. (Source: https://gazette.com/editorial-cuboulder-s-separate-but-equal-segregated-dorm/article_b809840d59e9-544c-830e-f1e230a4adaf.html)

\section{COLORBLIND RACISM}

We intend this first image not as a picture of the infrastructure of segregation that it depicts, but as a reminder of the range of trades involved in that infrastructure's realization. A number of people participated in imagining, locating, 
drawing, specifying, purchasing, installing, and maintaining these water fountains that reinforced an imagined difference between people with more or less dark skin. This is to say nothing of the impact of this infrastructure on those who saw, used, and see it.

If we presume that architects were involved in the realization of these fountains, we imagine they occupied one or more of the following positions: they may have not thought much of what they drew on their plans, because it was "how things were done"; they may have disliked the use of separate water fountains, but included them because "they were required to"; they may have drawn them with a sense of purpose because they believed in the ideologies that segregation reflects; or they may have used their design to "promote equality" by providing both races with equal access to safe water. Ibram Kendi defines racism as, "the marriage of racist policies and racist ideas that produces and mornalizes racial inequities." In each scenario, the architect perpetuates racism. Kendi defines a racist as, "one who is supporting a racist policy through their actions or inaction or expressing a racist idea." With this definition, in each of these scenarios, the architect is racist.

How those architects would have reacted to this label is useful for us to consider. Their discomfort stems from being labeled as someone who prejudices and harms the racial other. Writing on the subtle operations of racism, Eduardo Bonilla Silva notes, "whereas for most whites racism is prejudice, for most people of color racism is systemic or institutionalized." With this distinction, we see that architects participating in a system of institutionalized segregation (in this case) are participating in racism. How they framed or justified their work--as apathetic, forced, supremacist, or reformist--is irrelevant to the racism they shape.

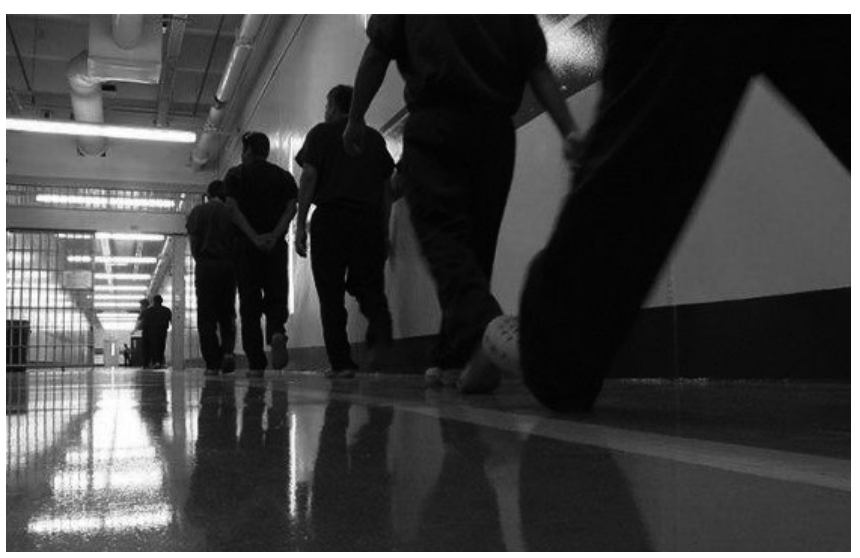

Figure 2. Controlling and disciplining bodies. (Source: https://www. bbc.com/news/av/magazine-26843600/inside-america-s-2bnimmigrant-detention-industry)
Spaces of overt racism persist. This vignette is intended as an obvious representation of ideologies that exist in less obvious representations (such as those figured below). Prison design is an articulation of racist ideologies that are expressed beyond prison walls. Back and brown bodies are criminalized in white spaces (e.g. white-dominated suburbs) and in black spaces (e.g. underserved inner-city neighborhoods). The segregation that occurs with white residents reporting black neighbors to the police is spatial in similar ways that paint stripes on prison floors restrict the privilege of movement for black bodies. Analogously, the segregation that occurs with police arresting black youth for possession of marijuana is spatial in ways similar to a prison's inescapable space of inevitable violent and arbitrary punishment.

Before the civil rights movement ended Jim Crow racist policies, the privilege of mobility and freedom from harassment were officially withheld from black bodies. But what was official and regulated then is hegemonic and entrenched now. "Instead of saying as they used to say during the Jim Crow era that they do not want us as neighbors, they say things nowadays such as 'I am concerned about crime, property values and schools;" Bonilla-Silva adds, "this new [colorblind racist] ideology has become a formidable political tool for the maintenance of the racial order." Seeing the architecture of prisons in connection to the architecture of spaces beyond their walls implores a broader view of racism in architecture. Architecture's racial discrimination is not restricted to a typology in the same way that prejudice is not restricted to individuals. Architecture's racism is institutionalized and systemic.

Until we accept this premise, we perpetuate a hegemonic racism.

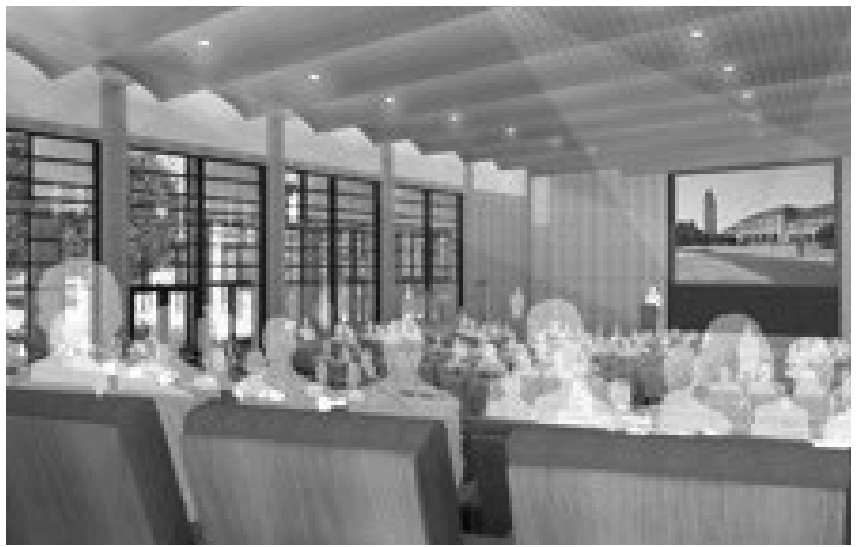

Figure 3. White hegemonic space. (Source: rendering of the Everett and Jane Hauck Auditorium of the Hoover Institution at Stanford University, CA, https://www.hoover.org/events/century-ideas-taxand-monetary-reform-ideas-actions-over-one-hundred-years) 


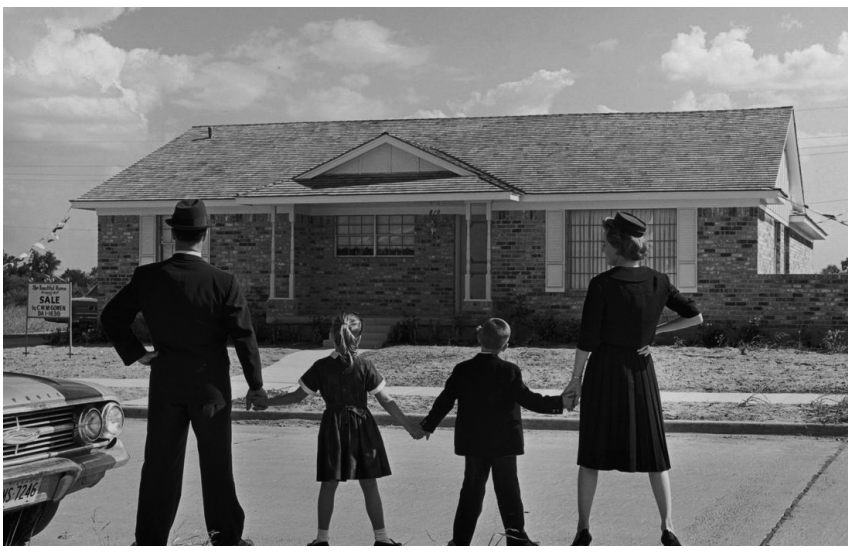

Figure 4. Designing normativity. (Source:https://www.thespruce.com/ ranch-house-plans-for-america-177540)

Sociologist of social movements, Joyce Bell, describes courtrooms as "white hegemonic space." Writing about tactics that black liberation activists used in courtrooms in the late 1960s, Bell describes courtroom architecture as part of a racist justice system. Black activists on trial used their bodies--their appearance, location, and movement--as political tactics to counter the courtroom's racializing strategies. Those strategies, expressed in architecture, leveraged hierarchy and power inequality, symbolism through portraiture of white justices, and the placement of disciplining bodies in strategic locations in the room. "The courtroom-operating as hegemonic white space-was a site of contestation by Black Power activists who found ways to challenge the legal, ideological, and physical space of the courtroom." Purportedly just and equitable, the architecture of the courtroom reflects colorblind racism's ability to maintain a racial order. The contrast between the colorblind architecture of the courtroom and the overtly racist architecture of the prison (Figure 2) indicates how design figures in white hegemony.

As a thought experiment, we invite the reader (as we invited the participants at the discussion at the ACSA meeting) to consider ways colorblind racism may be evident in the rendering shown above (in Figure 3). The whiteness of the silhouettes is perhaps the least relevant detail. The homogeneity of white silhouettes may be a more compelling way to start to think about color blindness in how architects literally and figuratively render space. The persistence of hierarchy, limits on mobility and circulation, the physical manifestation of an arguably oppressive form of pedagogy, and the institutional context of the Hoover Institution, located at Stanford University are other potent starting points for this experiment.

We invite the reader to consider the sequence of segregation that begins with the image of the water fountains (Figure 1), expands with the image of the prison (Figure 2), and lands with the image of the Everett and Jane Hauck Auditorium (Figure 3). The forms of racism vary in this sequence. To some, they become less visible but to others, more unbearable. We designed racist spaces of segregation during Jim Crow; we design racist spaces of unjust punishment under the New Jim Crow of incarceration of black and brown bodies; and (with or without knowing it), in many cases, we design racist spaces of what Bell calls out as the white hegemony of institutional spaces.

Architecture operates through media that reproduce its significance. Images like the one shown here (Figure 4) perpetuate hegemonic ideologies about who belongs in space and who space belongs to. We consider our social responsibility as architects tied up with ways the spaces we design are reproduced. Our design work, our renderings of users in buildings, and marketing shoots involving buildings we design all serve to encourage access to some while discouraging access to others. As an illustration of the power of this imagination that we help produce, consider the following passage by Claudia Rankine from Citizen: An American Lyric.

The new therapist specializes in trauma counseling. You have only ever spoken on the phone. Her house has a side gate that leads to a back entrance she uses for patients. You walk down a path bordered on both sides with deer grass and rosemary to the gate, which turns out to be locked.

At the front door the bell is a small round disc that you press firmly. When the door finally opens, the women standing there yells, at the top of her lungs, Get away from my house! What are you doing in my yard?

It's as if a wounded Doberman pinscher or a German shepherd has gained the power of speech. And though you back up a few steps, you manage to tell her you have an appointment. You have an appointment? she spits back. Then she pauses. Everything pauses. Oh, she says, followed by, oh, yes, that's right. I am sorry.

I am so sorry, so, so sorry.

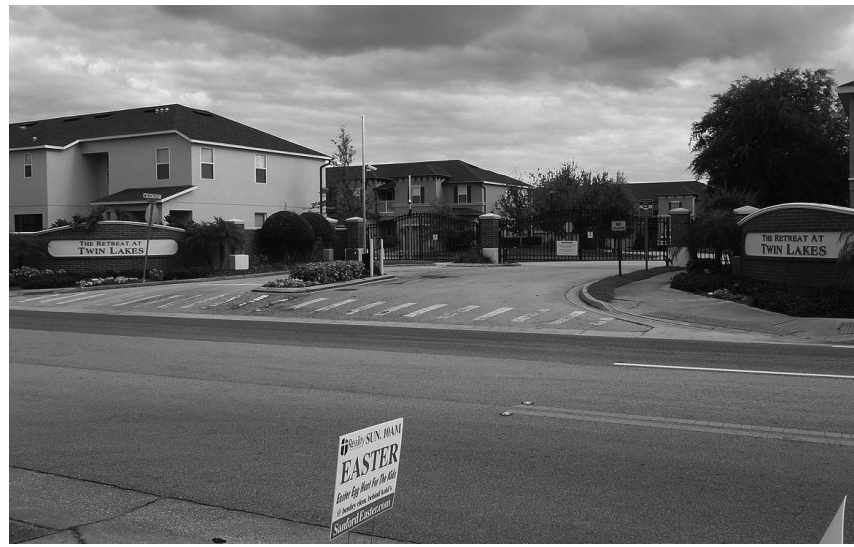

Figure 5. Twin Lakes Community, Sanford, FA. (Source: public domain image provided by Mt6617 on Wikimedia) 


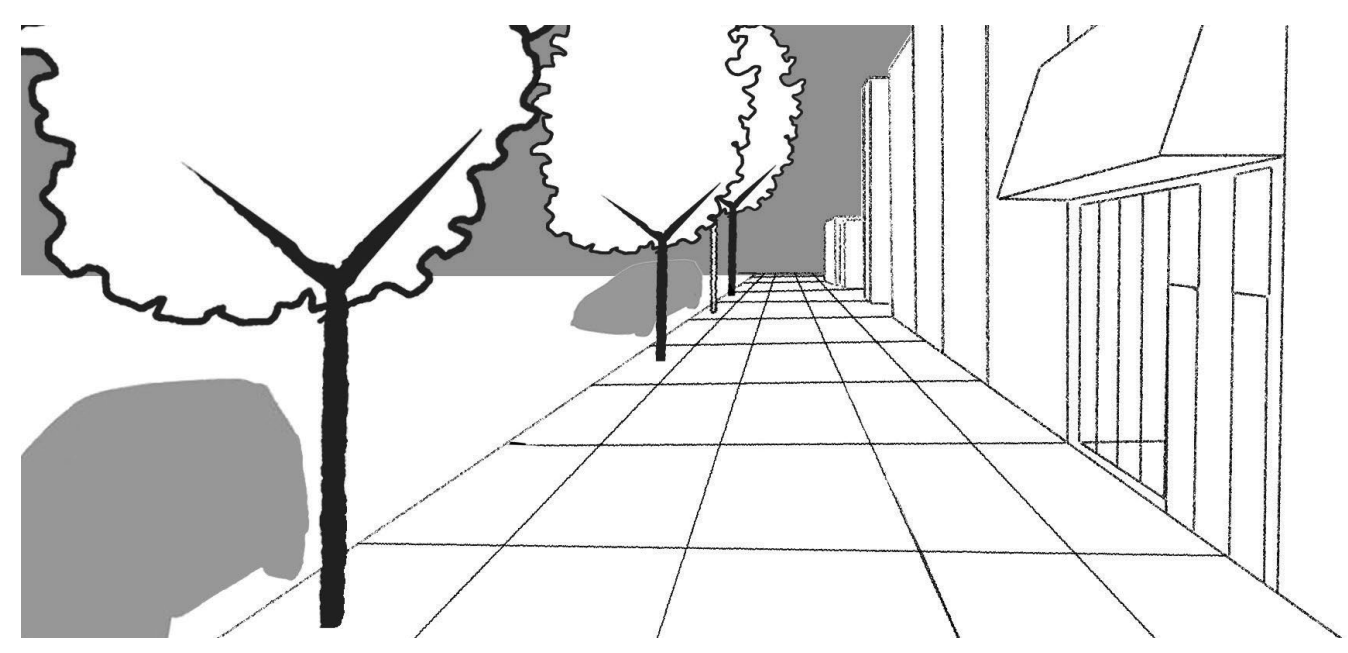

(a)

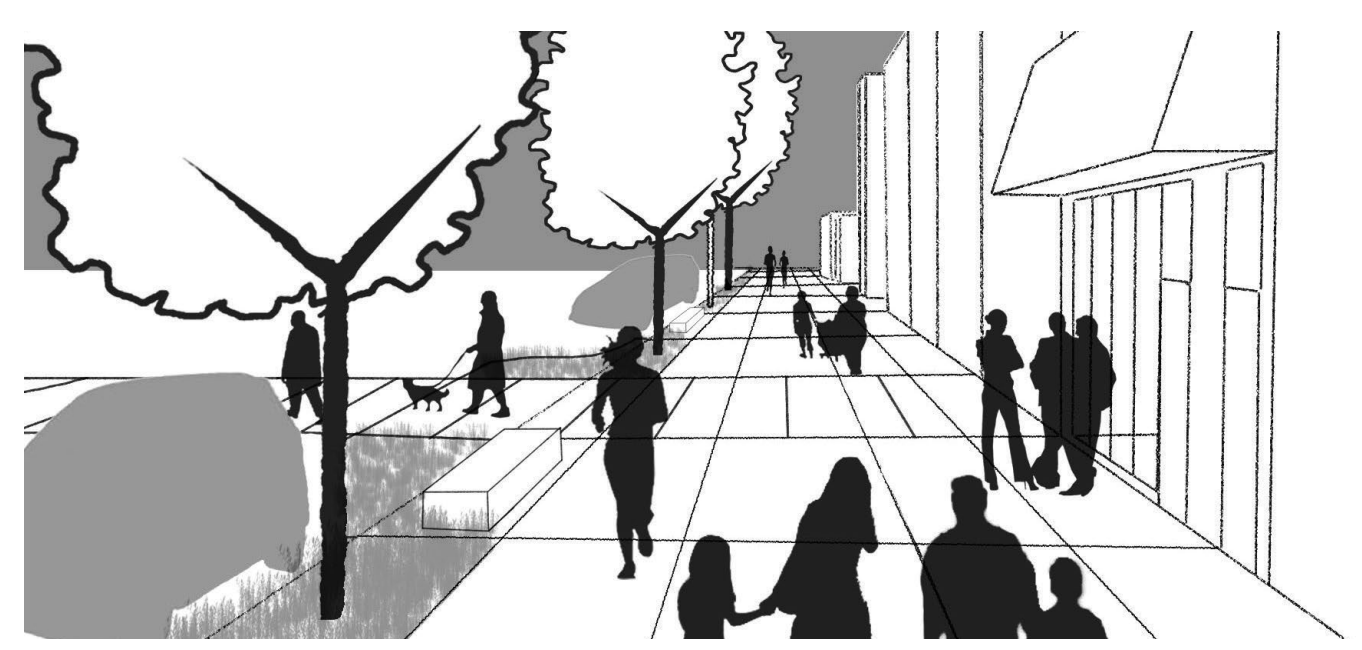

(b)

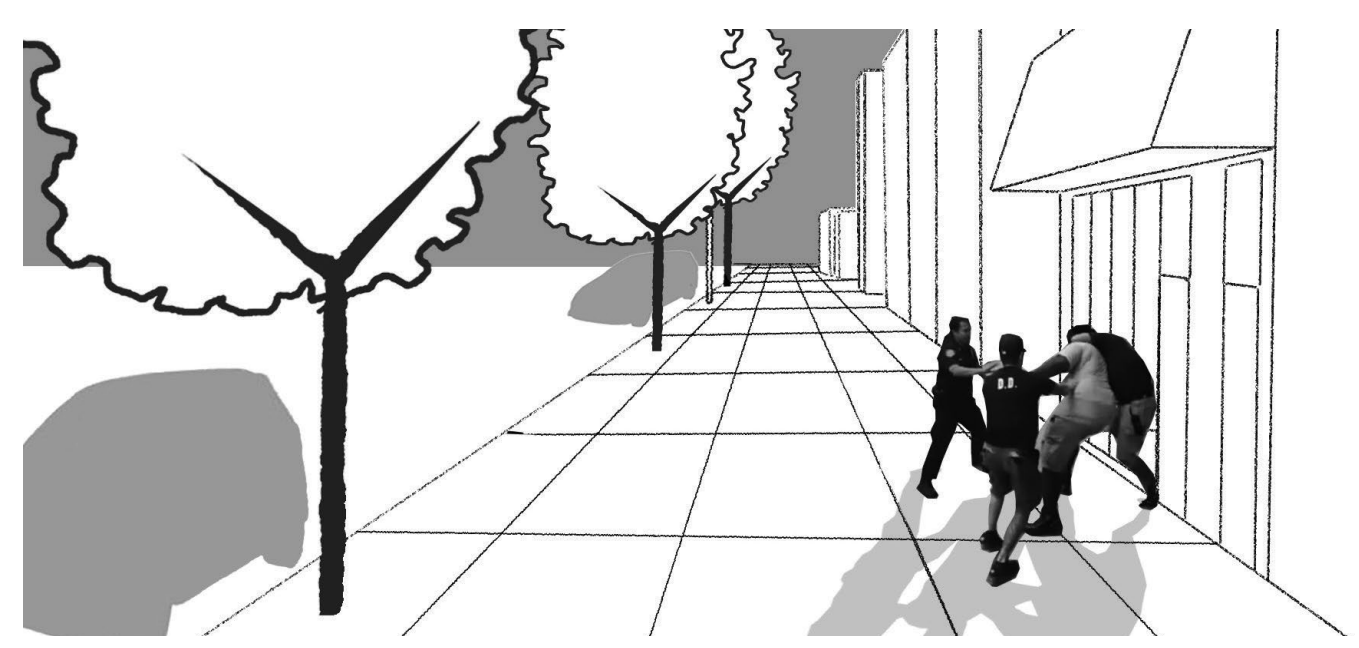

(c) 
Our failure to see the racialization of the spaces we imagine is an expression of colorblind racism. Bonilla-Silva argues that, "contemporary racial inequality is reproduced through 'new racism' practices that are subtle, institutional, and apparently nonracial." Just as the heteronormativity of space "lands with violence" upon the bodies of queer youth in certain spaces, so to does the colorblindness of space. The effects of an architectural or spatial colorblind racism range from indifference to discomfort to harm. (Liberation and empowerment are not present in this spectrum.

If we fail to see how a space like the Retreat at Twin Lakes is racialized, we fail to imagine an anti-racist position for architects. Twin Lakes is the designed space where Treyvon Martin's blackness was sufficient to draw attention, to create discomfort, and to justify his destruction.

\section{RENDERING SPACES COLORBLIND}

In our practices and our teaching, we conceptualize space as colorblind. We render those spaces as white, hegemonic, and normative. And we disengage when those spaces sustain racism. The next sequence of images (Figure 6) are reconstructions of the space on Staten Island where Eric Garner was killed on July 17, 2014. We intend for these reconstructions to mimic the technologies and visualizations that we use as architects and students to produce and share our designs. The center image (Figure 6-b) shows ways we render these spaces and construct an imagined occupation of space. Our active colorblindness often reveals itself forcefully at this stage of design. The image at the bottom (Figure 6 -c) depicts the racist killing of Eric Gardner in this space.

The question of whether the architecture--the product, the buildings, and streetscape--directly resulted in racial violence is not one we pose here. Rather, we ask if the services that architects employ in figuratively and literally rendering these spaces is racist.

Ibram Kendi defines racist policies as, "any [measures] that produces or sustain racial inequity between racial groups." And he defines policies as "written and unwritten laws, rules, procedures, processes, regulations, and guidelines that govern people." If we extrapolate from policy to architecture--with architecture representing regulations, guidelines, and spaces that govern people--Kendi's definitions tell us that the answer to the question posed above is yes.

The message that Ta-Nehisi Coates gives to his son and to his readers is that the violence of racism transcends most of our colorblind conceptions of racism and that it does so with extreme consequences:

But all our phrasing-race relations, racial chasm, racial justice, racial profiling, white privilege, even white supremacy-serves to obscure that racism is a visceral experience, that it dislodges brains, blocks airways, rips muscle, extracts organs, cracks bones, breaks teeth. You must never look away from this. You must always remember that the sociology, the history, the economics, the graphs, the charts, the regressions all land, with great violence, upon the body.

Add design to this list.

\section{FORMING ANTI-RACIST SPACES}

Eduardo Bonilla-Silva implores his readers, "[to] work to transition from the liberal stand (i.e., being a good, tolerant person) to becoming an antiracist. While the former stand cohabitates with racism-good people can harbor radicalized views and emotions, the latter stand requires a permanent war against racism." Similarly, we implore architecture students, practitioners, and educators to become anti-racist. Our goal with this paper is to contribute to efforts at defining ways we might do so.

At the 2019 ACSA Fall Conference, we organized a conversation that built on the ideas presented in this paper. After a brief presentation of the images and quotations above, we collectively explored our responses to the following prompts: As architectural educators, what tools might we use to become more conscious of racist and white hegemonic space? And what tactics might we employ to form anti-racist and counterhegemonic space?

Approximately twenty participants were tasked with sketching and analyzing spaces of the conference. Participants were asked to create a basic architectural drawing of their assigned space and then to identify aspects of their space that might reflect white hegemonic ideology. In groups of three, participants first created sketches of the room of the presentation, the foyer outside its door, the plaza at the entrance to the foyer, the entrance to the building complex, the apex of Stanford University's Oval Drive, and the entrance of the nearby Hoover Institution. Following this, with sheets of vellum, they overlaid ideas of elements in the space that were racist. Drawings included plans, sections, perspectives, and an exquisite corpse exercise. Participants considered basic elements of architecture, forms, use, symbols, program, material, hierarchy, circulation, and surveillance.

After working on these drawing exercises, we reconvened to discuss, first, how might we analyze architecture as racist; second, how we might decode white hegemonic space; and finally, how we might render space anti-racist.

Participants identified the spatial structure of the Beaux Artsinspired campus plan as an oppressive colonial model; the persistence of the white gaze of statues of white men that adorned buildings on a principal axis of the campus; the sense of confinement and exposure that topographic manipulations 
offered in primary circulation paths; the presence of cameras as indicative of surveillance that disproportionately affects persons of color; the alienating and deceptive hardness of one- and two-way glass surfaces adjacent to programmed outdoor spaces; the restrictive sense of mobility reinforced by limited access to buildings; the inherent racism of plan and section drawings as a form of expressing and analyzing space; and vegetation as welcoming in contrast to planting schemes that reinforce disciplined mobility. Our debate extended to a consideration of the design, construction, and uses of space in entrenching a white hegemonic order.

We see the conversations at the conference as a contribution to efforts by a range of architects, scholars, and activists in identifying and dissenting against the hegemony of white space. We seek to learn from and to join the efforts of those designers attempting to form anti-racist spaces. We hope the vignettes offered here provide some provocation in getting us all there.

\section{ENDNOTES}

1. Omi, Michael and Howard Winant. Racial Formation in the United States. Third ed. New York: Routledge/Taylor \& Francis Group, 2015.

2. The authors include an architectural designer, a student, and an educator. In addition to our identities as American, we also identify as Vietnamese, Mexican, and Iranian. Our racial and ethnic positions prevent us from understanding many expressions of racism in the US while simultaneously offering us some vantage. We strive to recognize ways we participate in forms of racism in our work, ways we benefit from privileges not afforded to others, and ways we might help articulate forms of racial injustice.

3. Kendi, Ibram X. How to be an Antiracist. First ed. New York: One World, 2019, pg. 18

4. Ibid, pg. 13. Emphasis added.

5. Bonilla-Silva, Eduardo. Racism without Racists: Color-Blind Racism and the Persistence of Racial Inequality in America. Fifth ed. US: Rowman \& Littlefield Publishers, 2017, pg. 8.

6. Alexander, Michelle. The New Jim Crow: Mass Incarceration in the Age of Colorblindness. New York: New Press, 2010.

7. Bonilla-Silva, Racism Without Racists, pg. 3.

8. Joyce Bell, "Black Power Law: the Courtroom as a Site of Resistance," Society for the Study of Social Problems, Annual Meeting, New York: August 2019.

9. The reference to forms of pedagogy draws from Paolo Friere's Pedagogy of the Oppressed.

10. Rankine, Claudia. Citizen: An American Lyric. Minneapolis, Minnesota: Graywolf Press, 2014, pg. 18

11. Bonilla-Silva, Racism Without Racists, pg. 3. Emphasis added.

12. Kendi, How to be Antiracist, pg. 18

13. Ibid.

14. Coates, Ta-Nehisi. Between the World and Me. First ed. New York: Spiegel \& Grau, 2015, pg. 10.

15. Bonilla-Silva, Racism Without Racists, pg. 243. 